\title{
Efficacy and Safety of Remogliflozin Etabonate, a New Sodium Glucose Co-Transporter-2 Inhibitor, in Patients with Type 2 Diabetes Mellitus: A 24-Week, Randomized, Double-Blind, Active-Controlled Trial
}

\author{
Mala Dharmalingam ${ }^{1}$ - S. R. Aravind ${ }^{2} \cdot$ Hemant Thacker $^{3} \cdot$ S. Paramesh ${ }^{4} \cdot$ Brij Mohan $^{5} \cdot$ Manoj Chawla $^{6}$. \\ Arthur Asirvatham $^{7} \cdot$ Ramesh Goyal $^{8} \cdot$ Jayashri Shembalkar $^{9} \cdot$ R. Balamurugan ${ }^{10} \cdot$ Pradnya Kadam $^{11} \cdot$ Hansraj Alva $^{12}$. \\ Rahul Kodgule $^{13} \cdot$ Monika Tandon $^{13} \cdot$ Sivakumar Vaidyanathan $^{13} \cdot$ Amol Pendse $^{13} \cdot$ Rajesh Gaikwad $^{13}$. \\ Sagar Katare ${ }^{13} \cdot$ Sachin Suryawanshi ${ }^{13} \cdot$ Hanmant Barkate $^{13}$
}

Published online: 11 March 2020

(c) The Author(s) 2020

\begin{abstract}
Background Metformin is the first-line treatment for type 2 diabetes mellitus (T2DM), but many patients either cannot tolerate it or cannot achieve glycemic control with metformin alone, so treatment with other glucose-lowering agents in combination with metformin is frequently required. Remogliflozin etabonate, a novel agent, is an orally bioavailable prodrug of remogliflozin, which is a potent and selective sodium-glucose co-transporter- 2 inhibitor.

Objective Our objective was to evaluate the efficacy and safety of remogliflozin etabonate compared with dapagliflozin in subjects with T2DM in whom a stable dose of metformin as monotherapy was providing inadequate glycemic control. Methods A 24-week randomized, double-blind, double-dummy, active-controlled, three-arm, parallel-group, multicenter, phase III study was conducted in India. Patients aged $\geq 18$ and $\leq 65$ years diagnosed with T2DM, receiving metformin $\geq 1500 \mathrm{mg} /$ day, and with glycated hemoglobin (HbA1c) levels $\geq 7$ to $\leq 10 \%$ at screening were randomized into three groups. Every patient received metformin $\geq 1500 \mathrm{mg}$ and either remogliflozin etabonate $100 \mathrm{mg}$ twice daily (BID) (group 1, $n=225$ ) or remogliflozin etabonate $250 \mathrm{mg} \mathrm{BID}$ (group 2, $n=241$ ) or dapagliflozin $10 \mathrm{mg}$ once daily (QD) in the morning and placebo QD in the evening (group 3, $n=146$ ). The patients were followed-up at weeks 1 and 4 and at 4-week intervals thereafter until week 24. The endpoints included mean change in HbA1c (primary endpoint, noninferiority margin $=0.35$ ), fasting plasma glucose (FPG), postprandial plasma glucose (PPG), bodyweight, blood pressure, and fasting lipids. Treatmentemergent adverse events (TEAEs), safety laboratory values, electrocardiogram, and vital signs were evaluated.

Results Of 612 randomized patients, 167 (group 1), 175 (group 2), and 103 (group 3) patients with comparable baseline characteristics completed the study. Mean change \pm standard error (SE) in HbA1c from baseline to week 24 was $-0.72 \pm 0.09$, $-0.77 \pm 0.09$, and $-0.58 \pm 0.12 \%$ in groups 1,2 , and 3 , respectively. The difference in mean HbA1c of group 1 versus group 3 $(-0.14 \%, 90 \%$ confidence interval $[\mathrm{CI}]-0.38$ to 0.10$)$ and group 2 versus group $3(-0.19 \%$; $90 \% \mathrm{CI}-0.42$ to 0.05$)$ was noninferior to that in group $3(p<0.001)$. No significant difference was found between group 1 or group 2 and group 3 in change in FPG, PPG, and bodyweight. The overall incidence of TEAEs was comparable across study groups (group $1=32.6 \%$, group $2=34.4 \%$, group $3=29.5 \%$ ), including adverse events (AEs) of special interest (hypoglycemic events, urinary tract infection, genital fungal infection). Most TEAEs were mild to moderate in intensity, and no severe AEs were reported.

Conclusion This study demonstrated the noninferiority of remogliflozin etabonate 100 and $250 \mathrm{mg}$ compared with dapagliflozin, from the first analysis of an initial 612 patients. Remogliflozin etabonate therefore may be considered an effective and well-tolerated alternative treatment option for glycemic control in T2DM.
\end{abstract}

Trial Registration CTRI/2017/07/009121.

Electronic supplementary material The online version of this article (https://doi.org/10.1007/s40265-020-01285-0) contains supplementary material, which is available to authorized users.

Extended author information available on the last page of the article 


\section{Key Points}

Remogliflozin etabonate 100 and $250 \mathrm{mg}$ achieved greater reductions in glycated hemoglobin (HbA1c) and demonstrated noninferiority in reducing $\mathrm{HbA} 1 \mathrm{c}$ levels compared with dapagliflozin $10 \mathrm{mg}$ over 24 weeks.

The use of rescue medication was lower, and the proportion of patients achieving therapeutic glycemic response was higher, in patients receiving remogliflozin etabonate.

Reductions in blood glucose levels and bodyweight were also similar among the three study groups. No severe adverse events were observed.

Remogliflozin etabonate could be an effective and well-tolerated alternative treatment option for glycemic control in patients with type 2 diabetes mellitus.

\section{Introduction}

According to the International Diabetes Federation [1], 425 million people worldwide have diabetes mellitus (DM), accounting for two-thirds of adults aged 20-64 years, and the proportion of deaths due to DM before the age of 60 years ranges from 36 to $73 \%$ [1]. The ten countries with the highest prevalence of DM account for almost $60 \%$ of the global disease burden, with China (114 million people), India (73 million people), and the USA (30 million people) contributing to most of this [1]. Therefore, the management of DM through effective treatment interventions is of the utmost importance in the field of clinical research.

To achieve glycemic targets, multiple agents with complementary mechanisms are frequently required, and treatment for type $2 \mathrm{DM}$ (T2DM) is evolving. Metformin is the first-line treatment for T2DM [2-5], but many patients either cannot tolerate metformin or cannot achieve glycemic control with metformin monotherapy. Consequently, treatment with other glucose-lowering agents as monotherapy or in combination with metformin is required [3-7].

Sodium glucose co-transporter-2 (SGLT2) inhibitors are a new class of antidiabetic drugs. SGLT2 is primarily expressed on the luminal side of the renal proximal tubule and absorbs almost all glucose filtered in the glomerular filtrate. Glucose absorption by the SGLT2 receptor is considered a primary pathway for renal glucose reabsorption. Inhibition of this pathway thus enhances urinary glucose excretion and consequently reduces blood glucose levels. In addition, SGLT2 inhibitors have other advantages in patients with T2DM, including reductions in both bodyweight and blood pressure (BP). As this mechanism of action is independent of insulin sensitivity and metformin's mechanism of action, SGLT 2 inhibitors are considered important glucoselowering agents as monotherapy or in combination with other antidiabetic agents [8-10].

Remogliflozin etabonate, a novel agent, is an orally bioavailable prodrug of remogliflozin, which is a potent and selective inhibitor of SGLT2. Significant urinary glucose excretion has been observed with single doses of remogliflozin etabonate. Compared with other approved SGLT2 inhibitors such as dapagliflozin, canagliflozin, empagliflozin, which have longer half-lives, remogliflozin etabonate has a short elimination half-life and requires twice daily (BID) administration to obtain 24-h glucose-lowering effects [11-15]. Dapagliflozin is an approved SGLT2 inhibitor widely used in India [16].

The present phase III study aimed to evaluate the efficacy and safety of remogliflozin etabonate 100 and $250 \mathrm{mg}$ compared with dapagliflozin $10 \mathrm{mg}$ over 24 weeks of treatment in patients with T2DM for whom glycemic control with metformin monotherapy was inadequate. This paper discusses the first analysis of this study performed to evaluate the noninferiority of the two doses of remogliflozin etabonate compared with dapagliflozin.

\section{Methods}

\subsection{Trial Design and Oversight}

The study was conducted in accordance with the Declaration of Helsinki and International Conference on Harmonization guidelines for good clinical practice. The study protocol was reviewed and approved by the institutional ethics committee at each study site. Written informed consent was obtained from all patients prior to their enrolment into the study.

This was a randomized, double-blind, double-dummy, multicenter, active-controlled phase III clinical trial conducted at 55 sites in India between 1 December 2017 and 26 December 2018.

\subsection{Subjects}

To be eligible for the study, patients were aged $\geq 18$ and $\leq 65$ years, had been diagnosed with T2DM, were receiving a stable dose of metformin $\geq 1500 \mathrm{mg} /$ day as monotherapy for at least 8 weeks prior to screening, and had inadequate glycemic control (glycated hemoglobin $[\mathrm{HbA} 1 \mathrm{c}] \geq 7$ to $\leq 10 \%$ ) at screening. We excluded patients with a diagnosis of type $1 \mathrm{DM}$ or secondary DM, a history of metabolic acidosis or diabetic ketoacidosis, a body mass 
index $(\mathrm{BMI}) \geq 45 \mathrm{~kg} / \mathrm{m}^{2}$ at screening, or estimated glomerular filtration rate (eGFR) $<60 \mathrm{~mL} / \mathrm{min} / 1.73 \mathrm{~m}^{2}$.

Eligible patients entered at least 2 weeks of an openlabel lead-in period. During this time, all patients received a standard consultation for dietary and exercise modification in accordance with the applicable national/international guidelines, along with continuation of metformin at doses recorded during screening. The key laboratory assessments were repeated after the lead-in period before randomization to obtain accurate baseline values.

\subsection{Study Treatment}

Eligible patients were randomized into three groups to receive one of the following treatments: Remogliflozin etabonate $100 \mathrm{mg}$ (group 1) or $250 \mathrm{mg}$ (group 2) administered as one tablet BID for 24 weeks or (group 3) dapagliflozin $10 \mathrm{mg}$ as one tablet once daily (QD) in the morning for 24 weeks. Matching placebos were used to blind treatment allocation. The randomization scheme was computer generated, and treatment kits were identified by numeric codes. Treatments were assigned sequentially and centrally using an interactive web response system.

In addition, all patients continued to receive metformin, in an open-label manner, at the same dose that they were receiving at time of screening. The dose of metformin was unaltered throughout the study period. Balanced randomization was ensured in group 1 and group 2, and randomization was stratified for baseline HbA1c levels (7-7.9\%, 8-8.9\%, and $9-10 \%)$ at the randomization visit.

\subsection{Study Protocol}

The maximum period of study participation for any patient was approximately 29 weeks (3 weeks of screening, 24 weeks of double-blind treatment, and 2 weeks of followup after the last dose of study drug). Patients were required to visit the study site at weeks 1 and 4 after randomization, followed by visits every 4 weeks until week 24 . An additional follow-up visit for safety assessment was scheduled for 2 weeks (at the 26th week) after receiving the last dose of study drug.

A detailed medical history was obtained from patients/ caregivers at the screening visit. The clinical examination include a complete physical examination and measurement of bodyweight, height, BMI, waist circumference, vital signs (including pulse rate, supine $\mathrm{BP}$, and oral temperature), and laboratory assessment of $\mathrm{HbA1c}$, fasting plasma glucose (FPG), postprandial plasma glucose (PPG), and lipid parameters (total cholesterol [TC], lowdensity lipoprotein cholesterol [LDL-C], high-density lipoprotein cholesterol [HDL-C], and triglycerides [TG]).
These examinations were repeated at each study visit up to 24 weeks. FPG and lipids were assessed on samples collected before breakfast, whereas PPG was assessed on samples collected $2 \mathrm{~h}$ after breakfast as per standard clinical practice. These assessments were performed at a central laboratory. Additionally, patients received glucose meters to monitor their blood glucose levels at home (self-monitored blood glucose). All BP measurements were performed on the same arm, preferably by the same person after the subject had been sitting for $5 \mathrm{~min}$ at screening and supine for $5 \mathrm{~min}$ at all visits. Urine culture was conducted at every visit. Safety assessments of treatment-emergent adverse events (TEAEs), safety laboratory values, electrocardiogram (ECG), and vital signs were monitored and recorded.

\subsection{Outcomes}

The primary efficacy endpoint was mean change from baseline in HbA1c levels at week 24. Secondary endpoints included mean change from baseline in $\mathrm{HbA} 1 \mathrm{c}$ levels at week 12, proportion of patients achieving a therapeutic glycemic response (defined as $\mathrm{HbA} 1 \mathrm{c}<7 \%$ ) at 24 weeks, proportion of patients requiring rescue medication (defined as patients with FPG $>240 \mathrm{mg} / \mathrm{dL}$ at any time from baseline to week 12 or FPG $>200 \mathrm{mg} / \mathrm{dL}$ or $\mathrm{HbA} 1 \mathrm{c}>8 \%$ from week 12 to 24 ) during the 24 weeks of treatment, mean change from baseline in FPG and PPG levels at 12 and 24 weeks, mean change from baseline in total bodyweight after 12 and 24 weeks, mean change from baseline in fasting lipids (TC, LDL-C, HDL-C, and TG) at week 24, and mean change from baseline in systolic BP (SBP) and diastolic BP (DBP) after 24 weeks. Safety endpoints were TEAEs (including AEs of special interest, such as hypoglycemic events, urinary tract infection [UTI], and genital fungal infection), safety laboratory values, ECG, and vital signs.

\subsection{Definitions of Analysis Sets}

The per protocol (PP) analysis set included all subjects who were randomized, received at least one dose of study drug, completed the study, and did not have any major protocol deviations (e.g., intake of prohibited concomitant medications/therapy or failure to meet protocol-specified eligibility criteria after enrolment into the study).

The modified intent-to-treat (mITT) analysis set included all randomized patients who received at least one dose of study medication, who had a non-missing baseline measurement, and who had at least one post-baseline efficacy measurement for a primary efficacy variable.

The safety analysis set included all patients who were randomized and received at least one dose of study medication. 


\subsection{Statistical Analysis}

In total, 519 evaluable patients were required to provide a power of $90 \%$ for testing the noninferiority of either dose of remogliflozin etabonate (100 and $250 \mathrm{mg}$ ) with dapagliflozin $10 \mathrm{mg}$ at 24 weeks, with a noninferiority margin of $0.35 \%$ for $\mathrm{HbA} 1 \mathrm{c}$ change from baseline assuming a standard deviation (SD) of $1 \%$ and at significance level of $5 \%$. Assuming that approximately $15 \%$ of randomized patients would not be available for analysis, we included an initial 612 randomized patients in this first analysis.

Analysis of the primary and secondary endpoints was conducted using the mITT and PP sets. The comparison of remogliflozin etabonate versus dapagliflozin in change in HbA1c levels from baseline to week 24 was analyzed using a mixed-model repeated measure (MMRM) method. The MMRM model included data from all visits until week 24 and covariates (treatment, visit, HbA1c baseline, center, and treatment by visit interaction); an unstructured covariance matrix was used, which allowed adjustment for correlations between the time points within patients.

Mean changes from baseline to specified time points for the FPG, PPG, fasting lipids, and bodyweight endpoints were summarized and analyzed using the MMRM method in the PP and mITT sets. The proportion of subjects achieving therapeutic glycemic response and the proportion requiring rescue medication were summarized by treatment group and compared using the chi-squared test.

Sensitivity analyses on the primary efficacy endpoint included analysis of covariance (ANCOVA) with last observation carried forward to handle missing data with the original covariates of treatment, visit, $\mathrm{HbA} 1 \mathrm{c}$ baseline, center, and treatment by visit interaction on PP and mITT populations; ANCOVA with observed cases with the same covariates on the PP and mITT populations; and ANCOVA with original results including values on rescue medication.

The analysis of safety and tolerability was based on the safety analysis set. Safety data during the 24-week doubleblind treatment period and the 2-week safety follow-up period were evaluated and summarized descriptively. AEs were coded using the Medical Dictionary for Regulatory Activities (version 20.0) and were summarized by system organ class (SOC) and preferred term (PT). Subjects were counted only once for each PT and SOC and by the highest severity of an event. Laboratory evaluations were summarized with descriptive statistics at each visit, and change from baseline was summarized for each post-baseline visit. Descriptive statistics were used for vital sign results and ECG parameters, and changes from baseline were presented. The data were analyzed using SAS ${ }^{\circledR}$ version 9.4 or above. Continuous variables were presented as means \pm SD and categorical variables as frequencies and percentages.

\section{Results}

A total of 612 patients were randomized into three groups: (1) remogliflozin etabonate $100 \mathrm{mg} \mathrm{BID}, n=225$; (2) remogliflozin etabonate $250 \mathrm{mg} \mathrm{BID}, n=241$; and (3) dapagliflozin $10 \mathrm{mg} \mathrm{QD}, n=146$. Of the $445(72.7 \%)$ patients who completed the study, 167 (74.2\%) were from group 1, $175(72.6 \%)$ were from group 2, and $103(70.5 \%)$ were from group 3. Of the $166(27.1 \%)$ patients who were withdrawn from the study, 57 (25.3\%) were from group 1, 66 (27.4\%) were from group 2, and 43 (29.5\%) were from group 3. The overall dropout rate was high but similar between the three treatment groups. The most common reason was withdrawal by subject: $15.1 \%, 15.4 \%$, and $20.5 \%$ in groups 1,2 , and 3, respectively. One patient was incorrectly randomized; the investigational product was not dispensed, so the patient was not included in the safety population. Figure 1 is a CONSORT diagram showing the flow of patients. Drug compliance was $>95.0 \%$ for all study drugs and was highest (97.72\%) for remogliflozin etabonate $250 \mathrm{mg}$.

\subsection{Patient Characteristics}

The mean $\pm \mathrm{SD}$ age of patients was comparable across the treatment groups: $50.86 \pm 8.76$ years in group 1; $50.87 \pm 8.45$ years in group 2 ; and $50.15 \pm 9.90$ years in group 3. All patients enrolled in the study were Asian Indians. The distribution of men and women was similar across the treatment groups, with a slightly higher proportion of men than women in each group. Mean BMI, bodyweight, and height of patients was comparable across the treatment groups. The mean \pm SD HbA1c level at screening visit was $8.19 \pm 0.79 \%$ in group $1 ; 8.28 \pm 0.82 \%$ in group 2 ; and $8.26 \pm 0.81 \%$ in group 3 (Table 1 ).

\subsection{Efficacy}

\subsubsection{Primary Endpoint}

An overall reduction in mean $\mathrm{HbA1c}$ levels was seen at all visits across all the treatment groups. In the PP population, the least-squares mean $(\mathrm{LSM}) \pm$ standard error (SE) change from baseline in HbA1c levels at week 24 was $-0.72 \pm 0.093 \%$ in group $1,-0.77 \pm 0.090 \%$ in group 2 , and $-0.58 \pm 0.116 \%$ in group 3 . The difference in mean change from baseline in $\mathrm{HbA} 1 \mathrm{c}$ at 24 weeks between group 1 and group 3 was $-0.14 \%$ (95\% confidence interval [CI] -0.42 to $0.14 ; p=0.332$ ) and between group 2 and group 3 was $-0.19 \%$ (95\% CI -0.47 to $0.09 ; p=0.190)$. The $p$ value for noninferiority of both comparisons, namely group 1 versus group 3 and group 2 versus group 3 was $p<0.001$ for change in HbA1c at 24 weeks (Figs. 2a, 3a). Similarly, the 


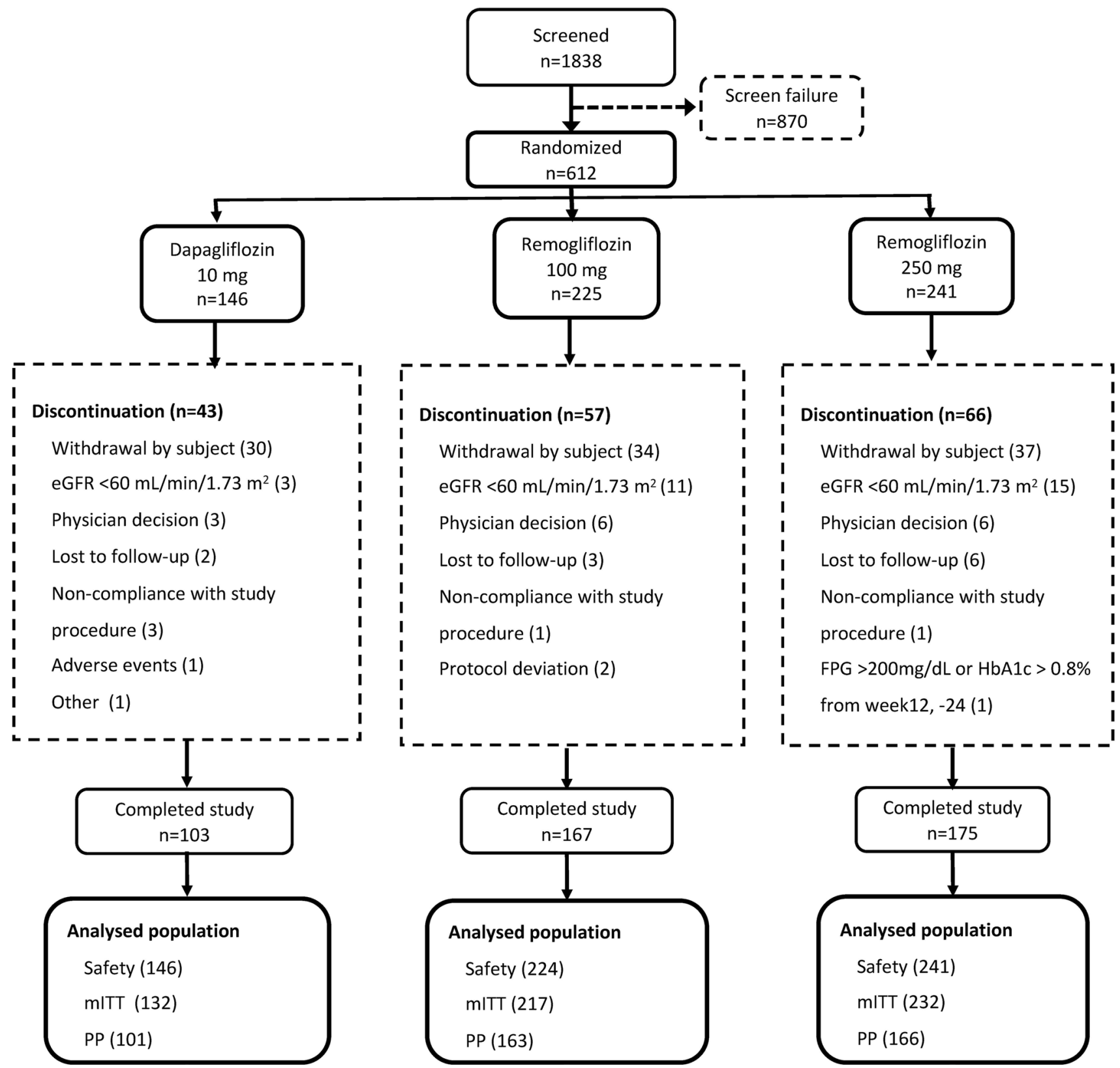

Fig. 1 CONSORT diagram. $e G F R$ estimated glomerular filtration rate, FPG fasting plasma glucose, HbAlc glycated hemoglobin, $m I T T$ modified intent-to-treat, $P P$ per protocol

mITT population showed that the LSM change \pm SE from baseline in HbA1c levels at week 24 was $-0.68 \pm 0.087$, $-0.73 \pm 0.083$, and $-0.62 \pm 0.109 \%$ in groups 1,2 , and 3 , respectively. The mean difference between both doses of remogliflozin etabonate and dapagliflozin (group 1 vs. 3 : mean difference $-0.07 \%$; $95 \% \mathrm{CI}-0.33$ to $0.20 ; p=0.626$; group 2 vs. group 3: mean difference $-0.11 \%$; $95 \%$ CI -0.37 to $0.15 ; p=0.406)$ was noninferior $(p=0.001$ and $p<0.001$, respectively) for both the comparisons (Figs. $2 \mathrm{~b}$, $3 b)$. Similar observations were noted using all sensitivity analyses in both PP and mITT populations.

\subsubsection{Secondary Endpoints}

In the PP and mITT populations, remogliflozin etabonate 100 and $250 \mathrm{mg}$ were noninferior to dapagliflozin $10 \mathrm{mg}$ in reducing $\mathrm{HbA} 1 \mathrm{c}$ levels from baseline at week 12 (PP: LSM difference in change $-0.09 \%$ [95\% CI -0.35 to 0.16 ; $p=0.479 ; p$ value for noninferiority $<0.001]$ and $-0.23 \%$ [95\% CI -0.48 to $-0.02 ; p=0.076, p$ value for noninferiority $<0.001]$, respectively, and mITT: LSM difference in change $-0.02 \%$ [95\% CI -0.25 to $0.22 ; p=0.870 ; p$ value for noninferiority $=0.001]$ and $-0.14 \%[95 \% \mathrm{CI}-0.37$ to 
Table 1 Demographic characteristics

\begin{tabular}{llll}
\hline Parameters & $\begin{array}{l}\text { Group 1 (REM } \\
100 \mathrm{mg} ; \\
n=224)\end{array}$ & $\begin{array}{l}\text { Group 2 (REM } \\
250 \mathrm{mg} ; \\
n=241)\end{array}$ & $\begin{array}{l}\text { Group 3 } \\
\text { (DAP 10 mg; } \\
n=146)\end{array}$ \\
\hline $\begin{array}{l}\text { Age (years) } \\
\text { Sex }\end{array}$ & $50.86 \pm 8.76$ & $50.87 \pm 8.49$ & $50.15 \pm 9.90$ \\
Male & $128(57.1)$ & $127(52.7)$ & $85(58.2)$ \\
Female & $96(42.9)$ & $114(47.3)$ & $61(41.8)$ \\
BMI $\left(\mathrm{kg} / \mathrm{m}^{2}\right)$ & $28.19 \pm 4.62$ & $27.82 \pm 4.77$ & $28.00 \pm 4.96$ \\
Bodyweight $(\mathrm{kg})$ & $71.24 \pm 11.63$ & $70.11 \pm 12.44$ & $72.10 \pm 12.81$ \\
Height $(\mathrm{cm})$ & $159.2 \pm 9.38$ & $158.9 \pm 8.78$ & $160.6 \pm 9.18$ \\
HbA1c $(\%)$ & $8.19 \pm 0.79$ & $8.28 \pm 0.82$ & $8.26 \pm 0.81$ \\
SBP $(\mathrm{mmHg})$ & $124.9 \pm 7.93$ & $124.5 \pm 8.69$ & $124.6 \pm 7.68$ \\
DBP $(\mathrm{mmHg})$ & $80.3 \pm 5.52$ & $79.6 \pm 5.59$ & $78.9 \pm 5.04$ \\
eGFR $\left(\mathrm{mL} / \mathrm{min} / 1.73 \mathrm{~m}^{2}\right)$ & & \\
Male & $87.9 \pm 18.91$ & $88.5 \pm 20.20$ & $89.1 \pm 15.73$ \\
Female & $88.5 \pm 19.06$ & $86.3 \pm 19.56$ & $87.3 \pm 17.92$ \\
\hline
\end{tabular}

Data are presented as $n(\%)$ or mean \pm standard deviation

$B M I$ body mass index, $D A P$ dapagliflozin, $D B P$ diastolic blood pressure, $e G F R$ estimated glomerular filtration rate, $H b A l c$ glycated hemoglobin, $R E M$ remogliflozin, $S B P$ systolic blood pressure

$0.09 ; p=0.244 ; p$ value for noninferiority $<0.001]$, respectively; Fig. 2c, d).

In the PP and mITT populations, the proportion of patients who achieved glycemic response was 46 and $36.4 \%$, 48.2 and $37.1 \%$, and 38.6 and $30.3 \%$ in groups 1,2 , and 3 , respectively. Similarly, the proportion of patients who used rescue medication in groups 1,2 , and 3 was 22.7 and $17.5 \%$, 15.7 and $12.1 \%$, and 26.7 and $21.2 \%$, respectively. However, the difference between the treatment groups was not statistically significant ( $p>0.05)$ (Fig. 4a, b).

Reductions in FPG and PPG concentrations from baseline were observed at weeks 12 and 24 in all treatment groups. In the PP population, for groups 1,2 , and 3 , the $\mathrm{LSM} \pm \mathrm{SE}$ change from baseline at week 24 in FPG concentrations was $-17.86 \pm 2.95,-20.94 \pm 2.93$, and $-20.23 \pm 3.59 \mathrm{mg} / \mathrm{dL}$ and in PPG concentrations was $-39.2 \pm 5.36,-41.5 \pm 5.28$, and $-32.4 \pm 6.54 \mathrm{mg} / \mathrm{dL}$, respectively. However, no statistically significant difference was observed in the mean difference in change from baseline between group 1 or group 2 and group 3. Similarly, in the mITT populations, no significant difference was observed between the treatment groups in $\mathrm{LSM} \pm \mathrm{SE}$ change from baseline in FPG $(-17.54 \pm 2.87,-20.51 \pm 2.80$, and $-20.45 \pm 3.47 \mathrm{mg} / \mathrm{dL})$ and PPG $(-37.2 \pm 5.12,-39.0 \pm 4.95$, and $-31.1 \pm 6.21 \mathrm{mg} /$ dL) concentrations at week 24 (Fig. 5a-d). Figure 5a-d present the mean change from baseline in FPG and PPG concentrations at week 12 for both PP and mITT populations.

The mean change $\pm \mathrm{SE}$ in total bodyweight at week 12 and 24 in group $1(-1.85 \pm 0.16$ and $-2.94 \pm 0.22 \mathrm{~kg})$, group $2(-2.13 \pm 0.15$ and $-3.17 \pm 0.22 \mathrm{~kg})$, and group 3 $(-2.09 \pm 0.19$ and $-2.8 \pm 0.28 \mathrm{~kg})$ were comparable in the mITT populations (Fig. 6).

No treatment- or dose-related trends were noted in terms of SBP and DBP. The reduction in mean SBP and DBP at
Fig. 2 Analysis of mean change in $\mathrm{HbA} 1 \mathrm{c}$ concentration from baseline at week 12 and week 24 across the treatment groups. Data shown as least-squares mean (95\% confidence interval); intergroup comparison $p$ value; group 1 , remogliflozin etabonate $100 \mathrm{mg}$; group 2, remogliflozin etabonate $250 \mathrm{mg}$; group 3, dapagliflozin $10 \mathrm{mg}$. Mean change in HbA1c concentration from baseline to week 24 of a PP population and $\mathbf{b}$ mITT population and from baseline to week 12 of $\mathbf{c}$ PP population and $\mathbf{d}$ mITT population. HbAlc glycated hemoglobin, IITT modified intent-to-treat, $P P$ per protocol
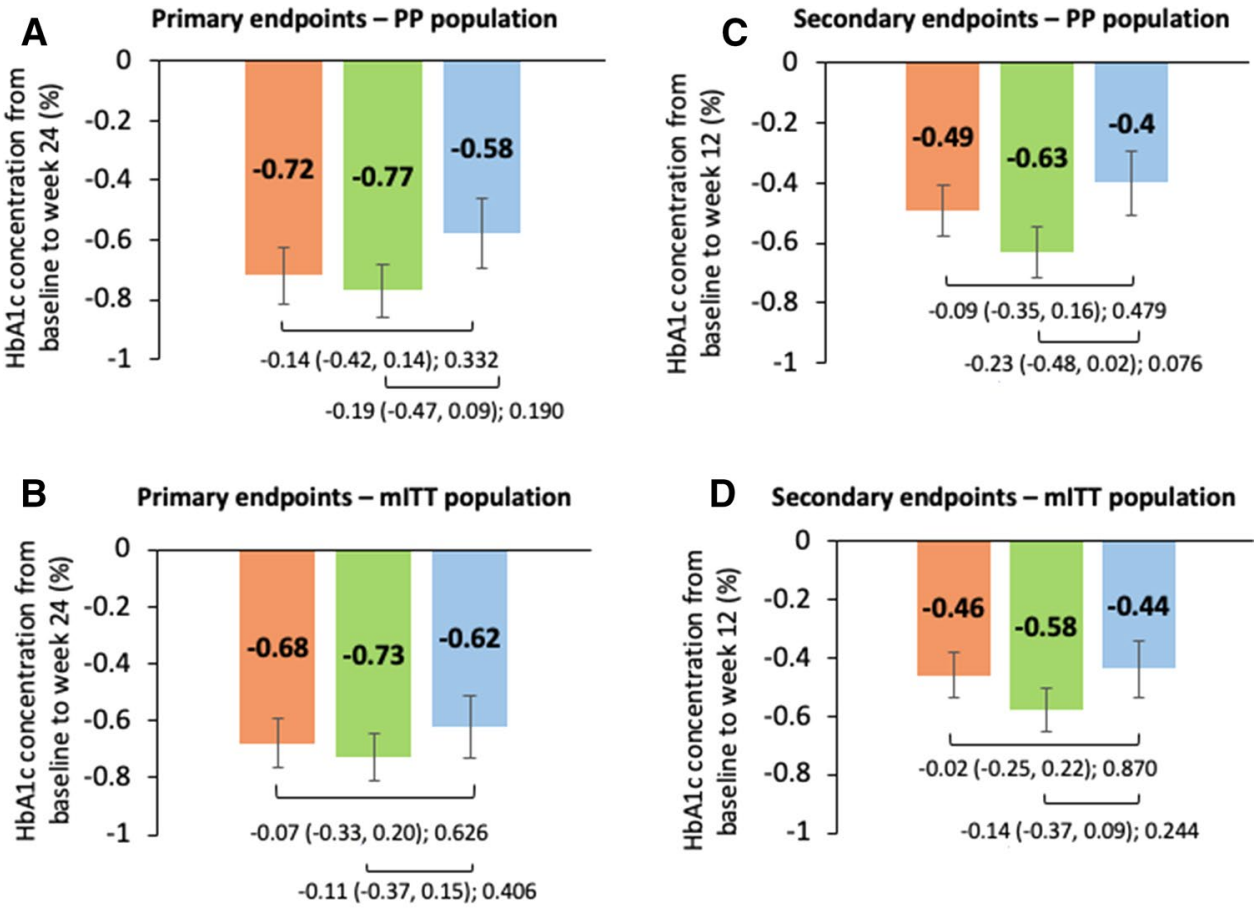

Group 1 Group 2 Group 3 


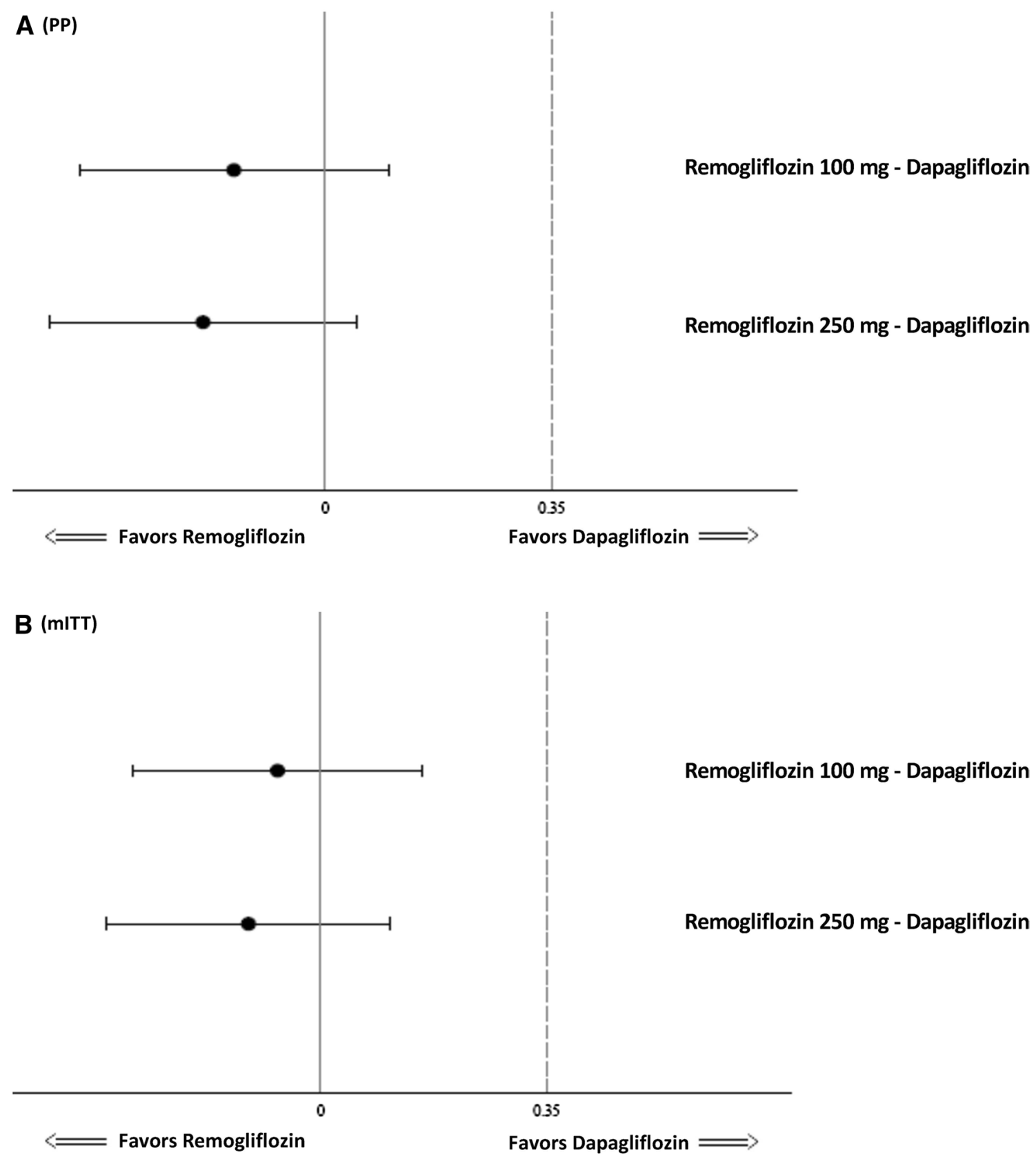

Fig. 3 Forest plot of treatment difference of mean change in HbAlc (\%) levels from baseline at 24 weeks (PP and mITT population). a PP: $p$ values of noninferiority for remogliflozin etabonate $100 \mathrm{mg}-$ dapagliflozin and remogliflozin etabonate $250 \mathrm{mg}$-dapagliflozin: $<0.001,<0.001$, respectively. $\mathbf{b}$ mITT: $p$ values of noninferiority

week 24 was as follows: group $1,-2.6$ and $-2 \mathrm{mmHg}$, group $2,-2.6$ and $-0.7 \mathrm{mmHg}$, group $3,-3.9$ and $-1 \mathrm{mmHg}$, respectively (Fig. 7).

No statistically significant difference in change from baseline in TC, LDL-C, HDL-C, TG, TC/HDL-C, or HDL-C/ LDL-C was observed between the treatment groups. The lipid profile parameters at the end of 12 and 24 weeks are presented in Table 2 and supplementary table 1, respectively. for remogliflozin etabonate $100 \mathrm{mg}$-dapagliflozin and remogliflozin etabonate $250 \mathrm{mg}$-dapagliflozin: $0.001,<0.001$, respectively. $H b A 1 c$ glycated hemoglobin, $m I T T$ modified intent-to-treat, $P P$ per protocol

\subsection{Safety}

The incidence of TEAEs was largely comparable across the three treatment groups at $32.6 \%, 34.4 \%$, and $29.5 \%$ in groups 1,2 , and 3 , respectively. The incidence of study drug-related TEAEs was comparable across the three treatment groups at $8.5 \%$ in group $1 ; 13.7 \%$ in group 2 ; and $6.8 \%$ in group 3 . Overall, TEAEs that led to permanent discontinuation of study drug 
Fig. 4 Mean change in difference in proportion of patients with $<7 \% \mathrm{HbA} 1 \mathrm{c}$ and patients using rescue medication at week 24. Data shown as leastsquares mean $(95 \%$ confidence interval); intergroup comparison $p$ value; group 1, remogliflozin etabonate $100 \mathrm{mg}$; group 2 , remogliflozin etabonate $250 \mathrm{mg}$; group 3, dapagliflozin $10 \mathrm{mg}$. $\mathbf{a}, \mathbf{b}$ Difference in proportion of patients with $<7 \% \mathrm{HbA} 1 \mathrm{c}$ and patients using rescue medication at week 24. HbAlc glycated hemoglobin, IITT modified intent-to-treat, $P P$ per protocol
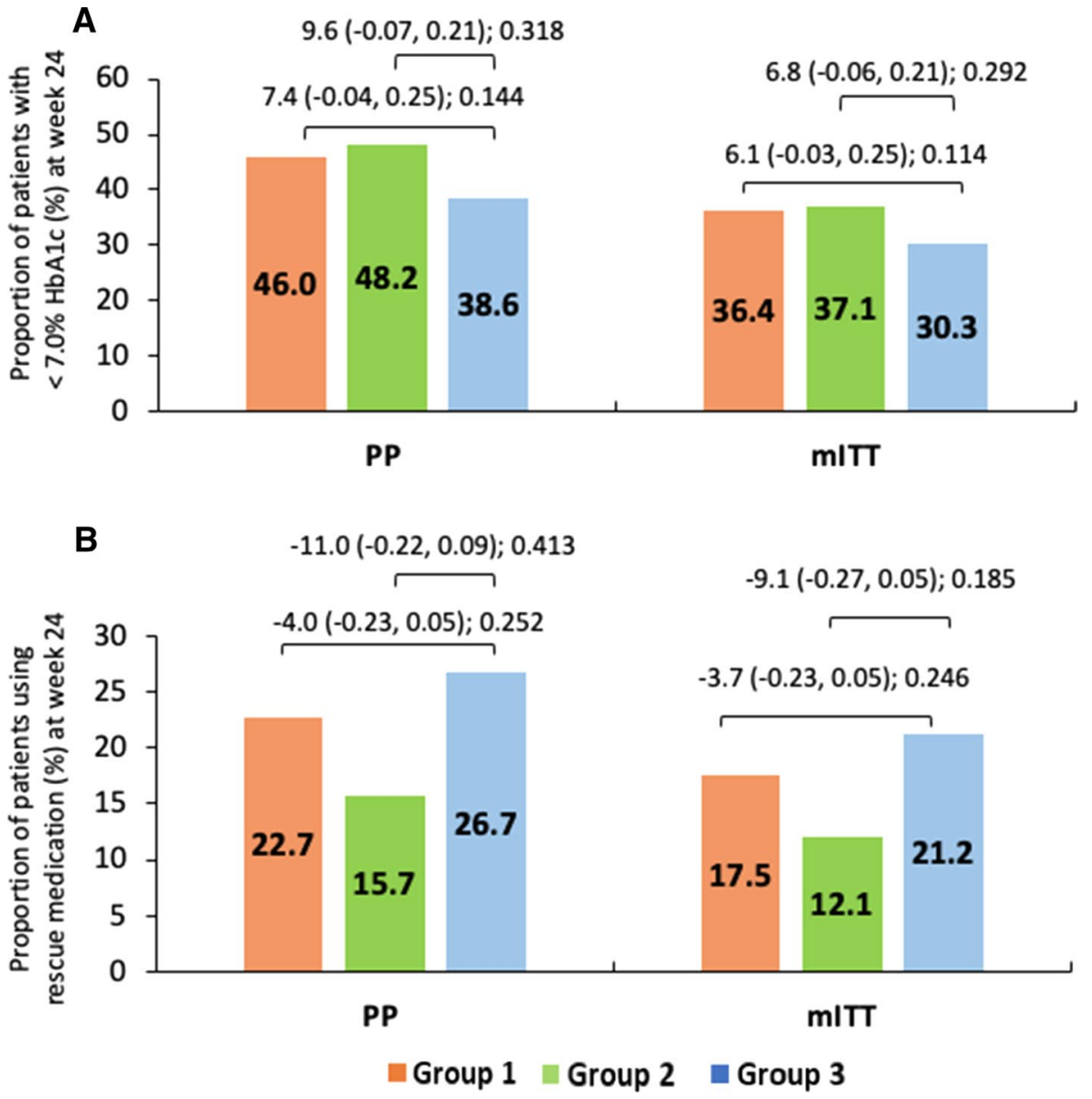

were reported in 11 patients ( $1.3 \%$ in group $1 ; 2.5 \%$ in group 2 ; and $1.4 \%$ in group 3 ) (supplementary table 2). No deaths or serious AEs (SAEs) occurred during the study period. With regards to the AEs of special interest (hypoglycemia, genital fungal infection, and UTI), no clinically relevant difference was found in the incidence of hypoglycemia $(1.3 \%, 0.4 \%$, and $1.4 \%$, respectively), genital fungal infections $(1.2 \%, 1.8 \%$, and $2.7 \%$, respectively), male UTI $(2.2 \%, 1.7 \%$, and $0.7 \%$, respectively), or female UTI $(0.9 \%, 5.0 \%$, and $1.4 \%$, respectively) (Table 3).

No treatment- or dose-related trends were noted in the clinical biochemistry, hematology, urinalysis, and vital signs data during the study. No clinically relevant difference was found in the vital signs, physical examination, 12-lead ECG, hematology, clinical biochemistry (including eGFR and serum creatinine), or urine analysis in groups 1 and 2 compared with group 3 (supplementary Table 3 ).

\section{Discussion}

This was a phase III clinical trial to evaluate the efficacy and safety of remogliflozin etabonate, a new SGLT2 inhibitor, compared with dapagliflozin in patients with T2DM. Remogliflozin etabonate 100 and $250 \mathrm{mg}$ was noninferior to dapagliflozin $10 \mathrm{mg}$ in reducing $\mathrm{HbA} 1 \mathrm{c}$ at week 24 . Overall, there was no clinically relevant or statistically significant difference between the three groups in reductions in $\mathrm{HbA1c}$, FPG, PPG, bodyweight, or BP in the proportion of patients achieving therapeutic glycemic response or the proportion of patients requiring rescue medication. AEs were comparable between the three groups.

Two recent trials that studied the safety and efficacy of remogliflozin etabonate (QD and BID) reported that the reduction in $\mathrm{HbA} 1 \mathrm{c}$ in patients receiving remogliflozin 
Fig. 5 Mean change in FPG and PPG concentrations from baseline at week-12 and - 24 across the treatment groups. Data shown as least-squares mean ( $95 \%$ confidence interval); intergroup comparison $p$ value; group 1 , remogliflozin etabonate $100 \mathrm{mg}$; group 2 , remogliflozin etabonate $250 \mathrm{mg}$; group 3, dapagliflozin $10 \mathrm{mg}$. Mean change in FPG concentration from baseline to week 12 and 24 of $\mathbf{a}$ PP and $\mathbf{b}$ mITT populations. Mean change in PPG concentration from baseline to week 12 and 24 of $\mathbf{c} P P$ and $\mathbf{d}$ mITT populations. FPG fasting plasma glucose, $\mathrm{HbAlc}$ glycated hemoglobin, IITT modified intent-to-treat, $P P$ per protocol, PPG postprandial plasma glucose

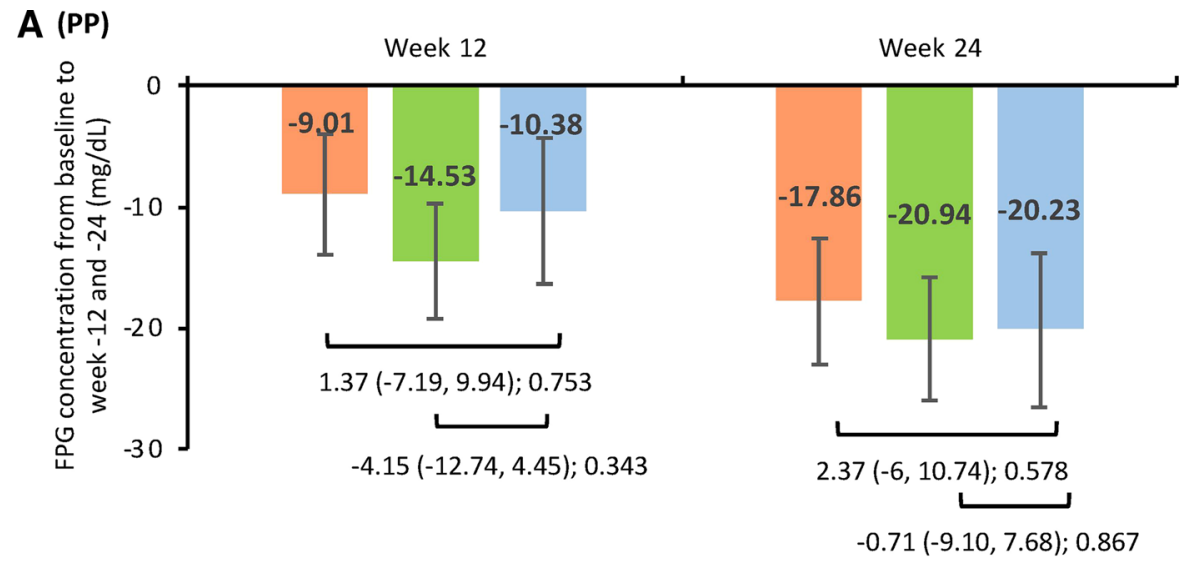

\section{B (mITT)}

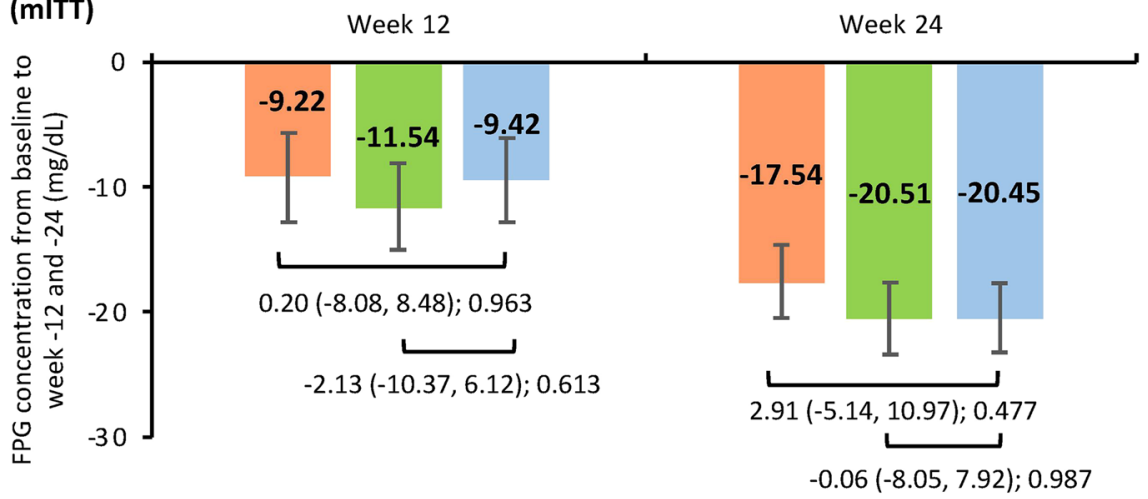

C (PP)

Week 12

Week 24
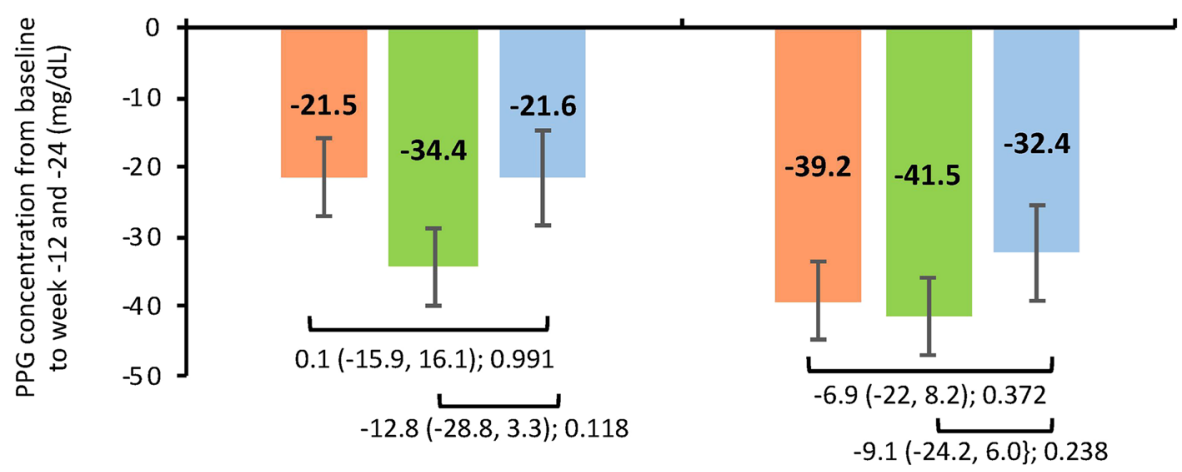

\section{D (mITT)}

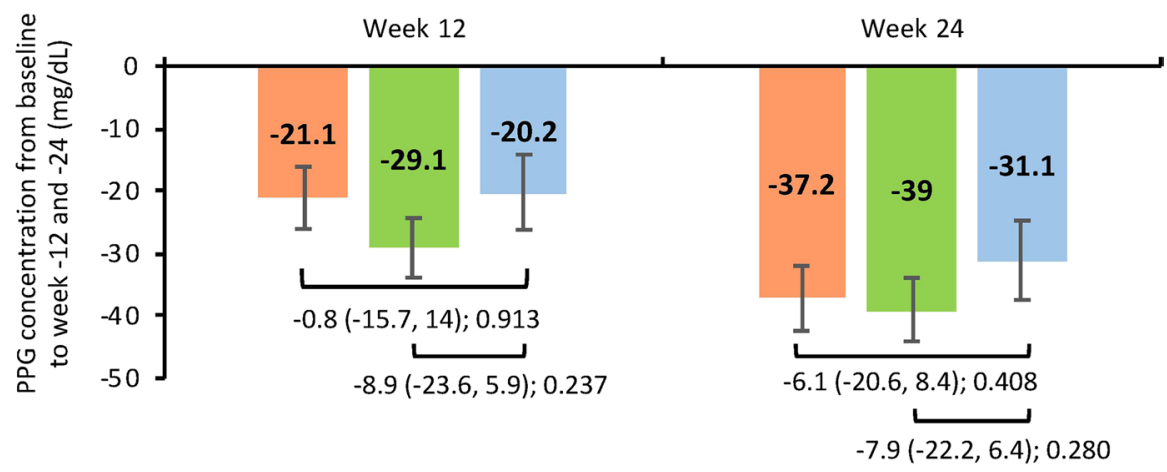

- Group 1 Group 2 @ Group 3 
Fig. 6 Mean change in bodyweight from baseline at week 12 and 24 across the treatment groups. Mean change in bodyweight from baseline to week 12 and 24 of modified intentto-treat population. Data shown as least-squares mean (95\% confidence interval); intergroup comparison $p$ value; group 1 , remogliflozin etabonate $100 \mathrm{mg}$; group 2, remogliflozin etabonate $250 \mathrm{mg}$; group 3 , dapagliflozin $10 \mathrm{mg}$

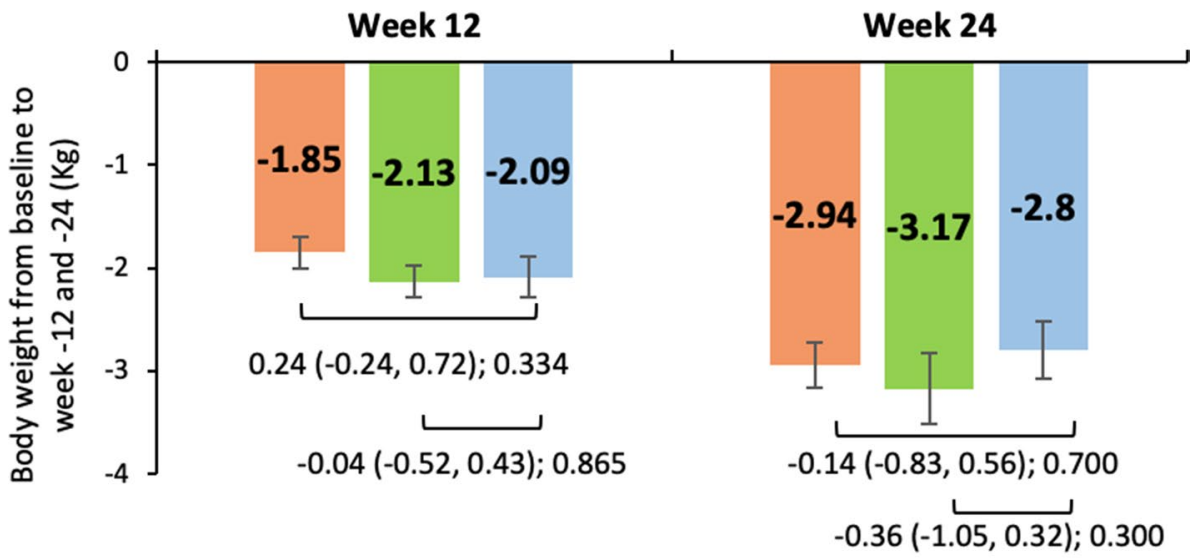

Group 1 Group 2 Group 3

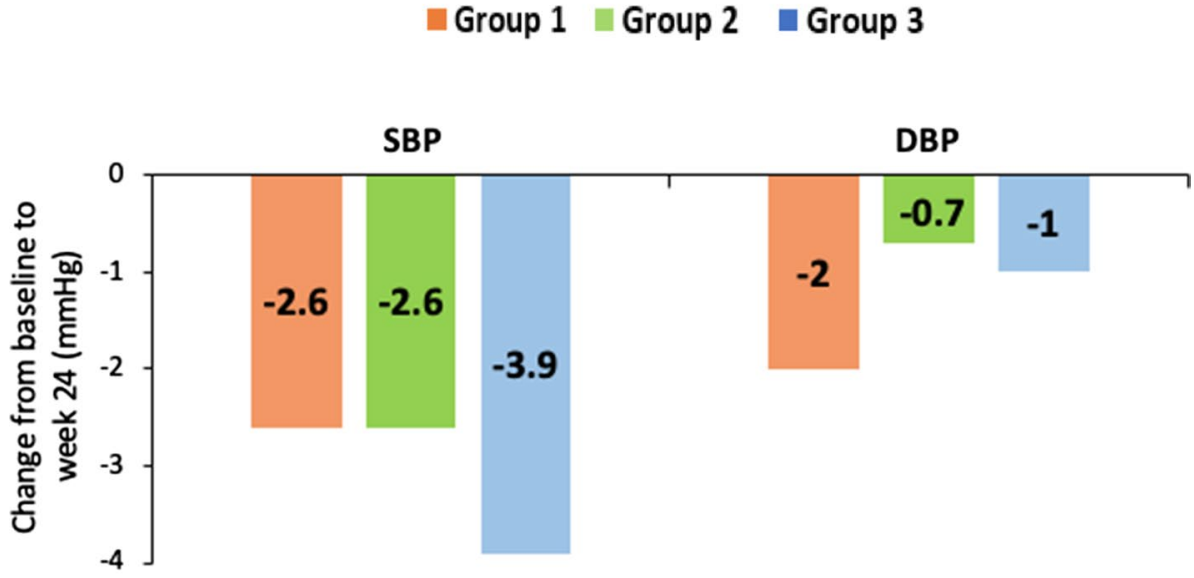

Group $1=$ Group $2 \square$ Group 3
Fig. 7 Mean change in SBP and DBP at week 24 across the treatment groups. Data shown as mean change from baseline to week 24 in SBP and DBP in safety population. Group 1 , remogliflozin etabonate $100 \mathrm{mg}$; group 2, remogliflozin etabonate $250 \mathrm{mg}$; group 3 , dapagliflozin $10 \mathrm{mg}$. $D B P$ diastolic blood pressure, $S B P$ systolic blood pressure

Table 2 Lipid parameters with remogliflozin 100 or $250 \mathrm{mg}$ vs. dapagliflozin $10 \mathrm{mg}$ (24 week)

\begin{tabular}{|c|c|c|c|c|c|}
\hline \multirow[t]{2}{*}{ At week 24} & \multicolumn{3}{|c|}{ Mean change from baseline } & \multicolumn{2}{|c|}{ Between-group difference ( $95 \% \mathrm{CI}) ; p$ value } \\
\hline & $\begin{array}{l}\text { Group } 1 \text { (REM } \\
100 \mathrm{mg} ; n=217)\end{array}$ & $\begin{array}{l}\text { Group } 2 \text { (REM } \\
250 \mathrm{mg} ; n=232)\end{array}$ & $\begin{array}{l}\text { Group } 3 \text { (DAP } \\
10 \mathrm{mg} ; n=132 \text { ) }\end{array}$ & $\begin{array}{l}\text { Group } 1 \text { vs. } 3 \text { (DAP } 10 \mathrm{mg} \text { vs. } \\
\text { REM } 100 \mathrm{mg} \text { ) }\end{array}$ & $\begin{array}{l}\text { Group } 2 \text { vs. } 3 \text { (DAP } 10 \mathrm{mg} \\
\text { vs. REM } 250 \mathrm{mg} \text { ) }\end{array}$ \\
\hline Total cholesterol (mg/dL) & $-2.2 \pm 2.62$ & $0.3 \pm 2.55$ & $-7.1 \pm 3.18$ & $4.9(-2.4$ to 12.3$) ; 0.189$ & 7.4 (0.1 to 14.7$) ; 0.048$ \\
\hline LDL-C (mg/dL) & $4.8 \pm 2.29$ & $5.1 \pm 2.22$ & $-0.0 \pm 2.79$ & 4.8 ( -1.6 to 11.3$) ; 0.142$ & $5.1(-1.4$ to 11.5$) ; 0.121$ \\
\hline $\mathrm{HDL}-\mathrm{C}(\mathrm{mg} / \mathrm{dL})$ & $3.1 \pm 0.74$ & $3.9 \pm 0.72$ & $1.5 \pm 0.92$ & 1.5 ( -0.6 to 3.7$) ; 0.163$ & 2.3 (0.2 to 4.5$) ; 0.032$ \\
\hline Triglycerides (mg/dL) & $-11.3 \pm 4.93$ & $-11.3 \pm 4.78$ & $-14.2 \pm 5.99$ & 2.9 (- -11.0 to 16.8$) ; 0.681$ & $2.9(-10.9$ to 16.7$) ; 0.679$ \\
\hline Total cholesterol/HDL-C & $-0.36 \pm 0.07$ & $-0.31 \pm 0.07$ & $-0.32 \pm 0.09$ & $-0.04(-0.24$ to 0.16$) ; 0.687$ & $0.01(-0.18$ to 0.21$) ; 893$ \\
\hline HDL-C/LDL-C & $-0.00 \pm 0.03$ & $0.05 \pm 0.03$ & $0.00 \pm 0.04$ & $-0.00(-0.11$ to 0.10$) ; 0.925$ & 0.04 ( -0.06 to 0.14$) ; 0.393$ \\
\hline
\end{tabular}

Data are presented as mean \pm standard deviation unless otherwise specified

$C I$ confidence interval, $D A P$ dapagliflozin, $H D L-C$ high-density lipoprotein cholesterol, $L D L-C$ low-density lipoprotein cholesterol, $R E M$ remogliflozin

etabonate $500 \mathrm{mg}$ QD or $250 \mathrm{mg}$ BID was $0.34 \%$ and $0.59 \%$, respectively. Overall, patients treated with remogliflozin etabonate had significant reductions in HbA1c levels (0.5-1.0\%) compared with placebo after 12 weeks, and efficacy improved when the drug was administered BID [17, 18]. These observations corroborate the present study observations. Dobbins et al. [19] also concluded that administration of remogliflozin etabonate for 12 days was well-tolerated and resulted in clinically meaningful improvements in plasma glucose accompanied by changes in bodyweight and BP in patients with T2DM.

The SGLT2 inhibitors available on the market have been primarily studied in Caucasian populations, with only a small representation of Asian and Indian populations. Asian 
Table 3 Summary of adverse events

\begin{tabular}{|c|c|c|c|}
\hline AEs & $\begin{array}{l}\text { Group } 1 \text { (REM } 100 \mathrm{mg} \text {; } \\
n=224)\end{array}$ & $\begin{array}{l}\text { Group } 2 \text { (REM } 250 \mathrm{mg} \text {; } \\
n=241 \text { ) }\end{array}$ & $\begin{array}{l}\text { Group } 3 \text { (DAP } 10 \mathrm{mg} \\
n=146 \text { ) }\end{array}$ \\
\hline TEAEs & $73(32.6)$ & $83(34.4)$ & $43(29.5)$ \\
\hline AEs leading to discontinuation & $3(1.3)$ & $6(2.5)$ & $2(1.4)$ \\
\hline AEs considered related to IP & $19(8.5)$ & $33(13.7)$ & $10(6.8)$ \\
\hline Serious AEs & 0 & 0 & 0 \\
\hline AEs leading to death & 0 & 0 & 0 \\
\hline \multicolumn{4}{|l|}{ AEs $>2 \%$ in any group } \\
\hline Pyrexia & $10(4.5)$ & $3(1.2)$ & $1(0.7)$ \\
\hline Bacteriuria & $4(1.8)$ & $7(2.9)$ & $2(1.4)$ \\
\hline Viral URTI & $1(0.4)$ & $4(1.7)$ & $3(2.1)$ \\
\hline Decreased GFR & $1(0.4)$ & $7(2.9)$ & 0 \\
\hline Dyslipidemia & $3(1.3)$ & $5(2.1)$ & $5(3.4)$ \\
\hline Pain in extremity & $1(0.4)$ & $2(0.8)$ & $3(2.1)$ \\
\hline Dizziness & $1(0.4)$ & $1(0.4)$ & $3(2.1)$ \\
\hline Headache & $4(1.8)$ & $8(3.3)$ & $5(3.4)$ \\
\hline Ketonuria & $6(2.7)$ & $2(0.8)$ & $1(0.7)$ \\
\hline Cough & $2(0.9)$ & $5(2.1)$ & $3(2.1)$ \\
\hline \multicolumn{4}{|l|}{ UTI } \\
\hline Male & $5(2.2)$ & $4(1.7)$ & $1(0.7)$ \\
\hline Female & $2(0.9)$ & $12(5.0)$ & $2(1.4)$ \\
\hline \multicolumn{4}{|l|}{ AEs of special interest } \\
\hline Hypoglycemia & $3(1.3)$ & $1(0.4)$ & $2(1.4)$ \\
\hline $\begin{array}{l}\text { Vulvovaginitis, balanitis, and } \\
\text { related genital infections }\end{array}$ & $4(1.8)$ & $3(1.2)$ & $4(2.7)$ \\
\hline UTI & $7(3.1)$ & $16(6.6)$ & $3(2.1)$ \\
\hline
\end{tabular}

Data are presented as $n(\%)$

$A E s$ adverse events, DAP dapagliflozin, GFR glomerular filtration rate, $I P$ investigational product, $R E M$ remogliflozin, TEAEs treatment-emergent AEs, URTI upper respiratory tract infection, UTI urinary tract infection

and Indian populations differ from Caucasian populations in terms of genetic make-up, BMI, and dietary habits, and the diabetes phenotype, risk for microvascular and macrovascular complications, and response to glucose-lowering agents all differ in Indian populations [20-22]. Hence, these results could not be extrapolated to non-Indian populations. Although, globally, the highest number of patients with DM are in India, no SGLT2 inhibitor has been separately studied in an Indian population. This is the first study to report the efficacy and safety of an SGLT2 inhibitor in a representative sample of an Indian DM population. A recent metaanalysis of 17 trials with Asian patients and 39 trials with non-Asian patients demonstrated no significant difference in the efficacy (reduction in $\mathrm{HbAlc}$ and bodyweight) or the risk of all-cause mortality or hypoglycemia with SGLT2inhibitor treatment between Asian and non-Asian patients with T2DM. In spite of the significant disparity in baseline BMI and bodyweight between Asian and non-Asian patients, there was no correlation between bodyweight reduction from baseline and $\mathrm{HbA} 1 \mathrm{c}$ changes from baseline or baseline weight or BMI in both Asian and non-Asian populations.
Various mechanisms thought to be responsible for the effect of SGLT2 inhibitors on bodyweight may include caloric loss through glucose excretion in the urine, the reduced total body fat and lean body mass and visceral adipose tissue, or improvements in weight-related quality of life [23].

The present study reported comparable reductions in bodyweight between the three groups, accounting for nearly $3 \mathrm{~kg}$, which is in concordance with bodyweight reductions observed with other SGLT2 inhibitors [24]. Sykes et al. [18] demonstrated parallel results showing significant reductions in bodyweight, ranging from 1.36 to $3.51 \mathrm{~kg}$ at week 12 in patients receiving remogliflozin etabonate compared with the placebo group $(p<0.015)$. They also reported increased serum LDL-C concentrations from baseline at week 12, with an increase in TC and HDL-C concentrations and a decreasing trend in TG concentrations [18]. A recent meta-analysis by Storgaard et al. [24] reported that SGLT2 inhibitors were associated with increased HDL-C compared with placebo $(0.05 \mathrm{mmol} / \mathrm{L}, 0.04-0.07 \mathrm{mmol} / \mathrm{L})$ and LDL-C $(0.09 \mathrm{mmol} / \mathrm{L}, 0.04-0.14 \mathrm{mmol} / \mathrm{L})$, and decreased TG $(-0.09 \mathrm{mmol} / \mathrm{L},-0.16$ to $-0.02 \mathrm{mmol} / \mathrm{L})$ [24]. In the 
present study, remogliflozin etabonate $250 \mathrm{mg}$ was associated with a greater increase in HDL-C than were dapagliflozin $10 \mathrm{mg}$ and remogliflozin etabonate $100 \mathrm{mg}$, but the difference was not significant. Both doses of remogliflozin etabonate had comparable effects in reducing TC, LDL$\mathrm{C}$, and TG after 24 weeks. However, conflicting observations from previous studies need further confirmation. Dose-dependent associations between the use of approved SGLT2 inhibitors and elevations in LDL-C concentrations is common. On the other hand, 12 weeks of remogliflozin etabonate QD showed no significant changes in the plasma levels of LDL-C, HDL-C, TC, or TG, whereas BID dosing at 250 and $500 \mathrm{mg}$ showed a significant increase in LDL-C and HDL-C levels, with reductions in TG concentrations $[17,18]$. Although increases in LDL-C with remogliflozin etabonate have not been attributed to any particular reason, it is important to consider its impact on cardiovascular events during the treatment of patients with T2DM.

The safety and tolerability of remogliflozin etabonate was in line with the known safety profile of SGLT2 inhibitors $[10,25]$. Hypoglycemia is a clinically important adverse effect of glucose-lowering agents and is more common when multiple glucose-lowering agents are co-administered. In this study, the incidence of hypoglycemia was comparable to that known for dapagliflozin, and none of the events were severe or required discontinuation from the study. None of the severe AEs were serious or considered drug related. No deaths or SAEs were reported. UTIs and genital infections are an area of special focus for studies of SGLT2 inhibitors. UTIs were reported in $2.1-6.6 \%$ of patients, with most patients experiencing only one incidence of UTI, and none of the UTIs led to discontinuation from the study. All AEs were of mild or moderate intensity and resolved either with self-treatment or responded readily to conventional interventions. The incidence of genital fungal infection was nondose-ordered and occurred at the lowest rate (1.2\%) in those receiving remogliflozin etabonate $250 \mathrm{mg}$. No new safety issues were identified with remogliflozin etabonate during this clinical study. The observations of two clinical trials are in alignment with those of the present study, which showed remogliflozin etabonate BID was well-tolerated in patients with T2DM $[17,18]$.

The results of this study should be interpreted in the context of some limitations. In total, $28 \%$ of the subjects did not complete the study so were not included in the PP analysis. The withdrawal rate was comparable between the three groups. We had estimated that 519 subjects would be required to achieve a power of $90 \%$ to demonstrate noninferiority assuming a $0 \%$ difference in the mean $\mathrm{HbA} 1 \mathrm{c}$ between the treatment groups. However, a higher rate of withdrawal than anticipated meant that 445 subjects were available for PP analysis. We did not perform a post hoc power estimation, as these are not considered useful [26].
However, the mean difference in HbA1c change from baseline was $-0.14 \%$ with remogliflozin etabonate $100 \mathrm{mg}$ and $-0.19 \%$ with remogliflozin etabonate $250 \mathrm{mg}$, in favor of remogliflozin compared with dapagliflozin. The CI of the mean difference extended up to $0.10 \%$ in the remogliflozin etabonate $100 \mathrm{mg}$ comparison and $0.05 \%$ in the remogliflozin etabonate $250 \mathrm{mg}$ comparison, far from the noninferiority margin of 0.35 , providing high significance levels of $<0.001$ for both comparisons. Thus, the results were definitive and not borderline. In addition, for noninferiority comparison, both PP and ITT analyses are considered equally important [27]. In the mITT population, 581 subjects were available for analysis, and noninferiority was clearly demonstrated with high statistical significance. Hence, we do not expect the higher withdrawal rate to have an impact on the noninferiority conclusion.

Increased blood glucose is associated with microvascular and macrovascular complications of diabetes, and reducing blood glucose is an important goal in the management of diabetes [28, 29]. Although the use of a placebo arm in the study would have helped in the estimation of a true treatment effect, ethical concerns regarding denial of available standard of care to patients with hyperglycemia led us to choose comparison with dapagliflozin as an active comparator. Dapagliflozin is an SGLT2 inhibitor approved in India for the treatment of T2DM and is standard of care for patients requiring treatment with an SGLT2 inhibitor. The efficacy and safety of dapagliflozin is well-established. The mean change from baseline $\mathrm{HbAlc}$ at week 24 of $-0.58 \%$, observed with dapagliflozin $10 \mathrm{mg}$, is in line with known $\mathrm{HbA} 1 \mathrm{c}$ reductions with dapagliflozin $10 \mathrm{mg}$ of $-0.57 \%$ ( $95 \% \mathrm{CI}-0.67$ to $-0.46 \%$ ) reported in a meta-analysis [30].

\section{Conclusion}

Remogliflozin etabonate significantly improved glycemic control in patients with T2DM inadequately controlled on metformin sustained over 24 weeks. Remogliflozin etabonate 100 and $250 \mathrm{mg}$ were both well-tolerated and effective, and efficacy was noninferior to dapagliflozin $10 \mathrm{mg}$ QD in the treatment of patients with T2DM. However, comparable effects on secondary endpoints need confirmation.

Acknowledgements The authors thank the study participants for their valuable contribution. We also thank Amit Pagada and Mahendra Rai (IQVIA Consulting and Information Services India Private Limited, Mumbai, India) for their medical writing assistance, funded by Glenmark Pharmaceuticals Limited (Mumbai, India). Study Investigators: Abhijeet Shinde (Lifepoint Multispeciality Hospital, Pune); Arthur Asirvatham (Arthur Asirvatham Hospital, Madurai); Arvind Kumar Misra (King George's Medical Institute, Lucknow); Ashutosh Goyal (Paras Hospital, Gurgaon); Avinash Kumbhar (Aster Aadhar Hospital, Kolhapur); Basavaprabhu (Department of Medicine, Kasturba Medical 
college Hospital, Mangalore); Bikas Saurabh (Department of Clinical Research, Paras HMRI Hospital, Patna); Bishwaroop Neogi (Surya Super Specialty Hospital, a unit of GV Meditech Private Limited, Varanasi); Bongi Vivekananda (Andhra Medical College, Visakhapatnam); Brij Mohan (BMC Hospital, Kanpur); Hemant Thacker (Bhatia Hospital, Mumbai); Chirag Rathod (Department of Medicine, GMERS Medical College and General Hospital, Vadodara); Deepak Bhosle (MGM Medical College and Hospital, Aurangabad); Dinesh Jain (Department of Medicine, Dayanand Medical College and Hospital, Ludhiana); Girithara Gopalkrishnan Jayraman Naidu (KG Hospital and Post Graduate Medical Institute, Coimbatore); Hansraj Alva (Vinaya Hospital and Research Centre, Mangalore); Hemanga Barman (M.V. Hospital for Diabetes Pvt. Ltd., Chennai); Hemant Gupta (Grant Government Medical College, Mumbai); J.B. Gupta (EHCC Eternal Heart Care Centre, Jaipur); Jayashri Shembalkar (Getwell Hospital and Research Institute, Nagpur); Jitendra Anand (Kanoria Hospital and Research Centre, Gandhinagar); Kamal Kumar Jain (Marwari Hospital and Research Center, Gowahati); Keyur Brahme (SSG Hospital and Medical College, Baroda); Kuntal Shah (Bodyline Hospitals, Ahmedabad); Mala Dharmalingam (M.S. Ramaiah Medical College and Hospitals, Bangalore); Manoj Chawla (BSES Municipal General Hospital, Mumbai); Manoj Kumar Srivastava (Om Surgical Center and Maternity Home, Varanasi); Mohan Magdum Jehangir (Clinical Development Centre Pvt. Ltd, Jehangir Hospital Premises, Pune); Neeraj Manikath (Govt. Medical College, Kerala); Nihal Thomas (Christian Medical College, Vellore); Pankaj Akholkar (GMERS Medical College, Ahmedabad); Paramesh Shamanna (Bangalore Diabetes Centre, Bangalore); Pradnya Kadam (Inamdar Multispecialty Hospital, Survey no 15, Fatima Nagar, Pune); Prakash Kurmi (Shivam Medical Hospital, Ahmedabad); Pravin Supe (Supe Heart and Diabetes Hospital and Research Centre, Nasik); R. Balamurugan Kovai (Diabetes Speciality Centre \& Hospital, Coimbatore); Ramesh Babu Pothineni (Ramesh Cardiac and Multispeciality Hospital (P) Ltd, Vijayawada); Ramesh Goyal (Apollo Hospitals International Limited, Gandhinagar); Ranjith V. Krishna (Rajendra Hospital, Mysore); S.R. Aravind (Diacon Hospital, Bangalore); S.K. Sharma (Diabetes Thyroid and Endocrine Centre, Jaipur); Sandeep Jain (Marudhar Hospital, Jaipur); Sandeep Julka (CHL Hospitals, Indore); Sandeep Kumar Gupta (M. V. Hospital and Research Centre, Lucknow); Saurabh Agarwal (GSVM Medical College, Kanpur); Shailaja Bhatia (Medipoint Hospitals Pvt Ltd, Pune); Shilpa Bawankule (Datta Maghe Institute of Medical Sciences, Wardha); Sudha Vidyasagar (Kasturba Hospital, Manipal); Sunil Naik (Department of Medicine, Rajiv Gandhi Institute of Medical Sciences \& RIMS Government General Hospital, Srikakulam); Sunil Tyagi (Ratandeep Multispeciality Hospital, Ahmedabad); Surendra Kumar (S.P. Medical College and Hospital, Bikaner); Swapnav Borthakur (Downtown Hospital, Kamrup); Urman Dhru (HCG Hospitals, Ahmedabad); Ved Prakash (Department of Endocrinology, Indira Gandhi Institute of Medical Sciences, Patna); Vineet Shukla (KRM Hospital and Research Center, Lucknow); Vipul Khandelwal (Apex Hospital Pvt. Ltd., Jaipur); Y. Sadasiva Rao (Yalamanchi Hospitals and Research Centres Pvt Ltd., Vijayawada); Yajnik Kumble (Omega Hospital, Mangalore).

\section{Compliance with Ethical Standards}

Funding This study was funded by Glenmark Pharmaceuticals Limited. Glenmark Pharmaceuticals Limited provided oversight of the study conduct, including design and the collection, compilation, and analysis of data.

Conflict of interest Rahul Kodgule, Monika Tandon, Sivakumar Vaidyanathan, Amol Pendse, Rajesh Gaikwad, Sagar Katare, Sachin Suryawanshi, and Hanmant Barkate are employees of Glenmark Pharmaceuticals Limited. Mala Dharmalingam, S.R Aravind, Hemant
Thacker, S. Paramesh, Brij Mohan, Manoj Chawla, Arthur Asirvatham, Ramesh Goyal, Jayashri Shembalkar, R. Balamurugan, Pradnya Kadam, and Hansraj Alva have no conflicts of interest that are directly relevant to the content of this article.

Open Access This article is licensed under a Creative Commons Attribution-NonCommercial 4.0 International License, which permits any non-commercial use, sharing, adaptation, distribution and reproduction in any medium or format, as long as you give appropriate credit to the original author(s) and the source, provide a link to the Creative Commons licence, and indicate if changes were made. The images or other third party material in this article are included in the article's Creative Commons licence, unless indicated otherwise in a credit line to the material. If material is not included in the article's Creative Commons licence and your intended use is not permitted by statutory regulation or exceeds the permitted use, you will need to obtain permission directly from the copyright holder.To view a copy of this licence, visit http://creativecommons.org/licenses/by-nc/4.0/.

\section{References}

1. International Diabetes Federation. IDF Diabetes Atlas, 8th edn. Brussels: International Diabetes Federation. 2017. http://www. diabetesatlas.org. Accessed 27 July 2019.

2. Rojas LB, Gomes MB. Metformin: an old but still the best treatment for type 2 diabetes. Diabetol Metab Syndr. 2013;5:6.

3. International Diabetes Federation Global guideline for type 2 diabetes. http://www.idf.org/global-guideline-type-2-diabetes-2012. Accessed 5 Sep 2013.

4. National Institute for Health and Clinical Excellence Type 2 diabetes: The management of type 2 diabetes (NICE clinical guideline 87). http://www.nice.org.uk/guidance/CG87. Accessed 15 Aug 2013.

5. Irons BK, Minze MG. Drug treatment of type 2 diabetes mellitus in patients for whom metformin is contraindicated. Diabetes Metab Syndr Obes. 2014;7:15-24.

6. Inzucchi SE, Bergenstal RM, Buse JB, Diamant M, Ferrannini E, Nauck M, et al. Management of hyperglycemia in type 2 diabetes: a patient-centered approach. Diabetes Care. 2012;35:1364-79.

7. Garber AJ, Abrahamson MJ, Barzilay JI, Blonde L, Bloomgarden ZT, Bush MA, et al. American Association of Clinical Endocrinologists' comprehensive diabetes management algorithm 2013 consensus statement. Endocr Pract. 2013;19:1-48.

8. Abdul-Ghani MA, Norton L, DeFronzo RA. Efficacy and safety of SGLT2 inhibitors in the treatment of type 2 diabetes. Curr Diabetes Rep. 2012;12:230-8.

9. Vallon V. The mechanisms and therapeutic potential of SGLT2 inhibitors in diabetes mellitus. Annu Rev Med. 2015;66:255-70.

10. Hsia DS, Grove O, Cefalu WT. An update on sodium-glucose co-transporter-2 inhibitors for the treatment of diabetes mellitus. Curr Opin Endocrinol Diabetes Obes. 2017;24:73-9.

11. Heise T, Seewaldt-Becker E, Macha S, Hantel S, Pinnetti S, Seman L, et al. Safety, tolerability, pharmacokinetics and pharmacodynamics following 4 weeks' treatment with empagliflozin once daily in patients with type 2 diabetes. Diabetes Obes Metab. 2013;15:613-21.

12. Heise T, Seman L, Macha S, Jones P, Marquart A, Pinnetti S, et al. Safety, tolerability, pharmacokinetics, and pharmacodynamics of multiple rising doses of empagliflozin in patients with type 2 diabetes mellitus. Diabetes Therapy. 2013;4:331-45.

13. Kasichayanula S, Liu X, Lacreta F, Griffen SC, Boulton DW. Clinical pharmacokinetics and pharmacodynamics of dapagliflozin, a selective inhibitor of sodium-glucose co-transporter type 2. Clin Pharmacokinet. 2013;53:17-27. 
14. Devineni D, Polidori D, Curtin C, Stieltjes H, Tian H, Wajs E. Single-dose pharmacokinetics and pharmacodynamics of canagliflozin, a selective inhibitor of sodium glucose cotransporter 2, in healthy indian participants. Clin Ther. 2016;38(89-98):e1.

15. Kapur A, O'Connor-Semmes R, Hussey EK, Dobbins RL, Tao W, Hompesch M, et al. First dose-escalation study with remogliflozin etabonate, a selective inhibitor of the sodium-glucose transporter 2 (SGLT2), in healthy subjects and in subjects with type 2 diabetes mellitus. BMC Pharmacol Toxicol. 2013;14:26.

16. Viswanathan V, Singh KP. Use of dapagliflozin in the management of type 2 diabetes mellitus: a real-world evidence study in Indian patients (FOREFRONT). Diabetes Technol Ther. 2019;21:415-22.

17. Sykes AP, Kemp GL, Dobbins R, et al. Randomized efficacy and safety trial of once-daily remogliflozin etabonate for the treatment of type 2 diabetes. Diabetes Obes Metab. 2014;98-98:101.

18. Sykes AP, O'Connor-Semmes R, Dobbins R, et al. Randomized trial showing efficacy and safety of twice-daily remogliflozin etabonate for the treatment of type 2 diabetes. Diabetes Obes Metab. 2015;17:94-7.

19. Dobbins RL, O'Connor-Semmes R, Kapur A, Kapitza C, Golor G, Mikoshiba I, et al. Remogliflozin etabonate, a selective inhibitor of the sodium-dependent transporter 2 reduces serum glucose in type 2 diabetes mellitus patients. Diabetes Obes Metab. 2012;14:15-22.

20. Unnikrishnan R, Anjana RM, Mohan V. Diabetes in South Asians: is the phenotype different? Diabetes. 2014;63:53-5.

21. Mehta SR, Kashyap AS, Das S. Diabetes mellitus in India: the modern scourge. Med J Armed Forces India. 2009;65:50-4.

22. Kaveeshwar SA, Cornwall J. The current state of diabetes mellitus in India. Australas Med J. 2014;7:45-8.
23. Cai X, Gao X, Yang W, Chen Y, Zhang S, Zhou L, et al. No disparity of the efficacy and all-cause mortality between Asian and non-Asian type 2 diabetes patients with sodium-glucose cotransporter 2 inhibitors treatment: a meta-analysis. J Diabetes Investig. 2018;9:850-61.

24. Storgaard H, Gluud LL, Bennett C, Grøndahl MF, Christensen MB, Knop FK, et al. Benefits and harms of sodium-glucose cotransporter 2 inhibitors in patients with type 2 diabetes: a systematic review and meta-analysis. PLoS One. 2016;11:e0166125.

25. Madaan T, Akhtar M, Najmi AK. Sodium glucose Co Transporter 2 (SGLT2) inhibitors: current status and future perspective. Eur J Pharm Sci. 2016;93:244-52.

26. Zhang Y, Hedo R, Rivera A, Rull R, Richardson S, Tue XM. Post hoc power analysis: is it an informative and meaningful analysis? Gen Psychiatry. 2019;32:e100069.

27. Non-Inferiority Clinical Trials to Establish Effectiveness Guidance for Industry. U.S. FDA. November 2016. https://www.fda. gov/regulatory-information/search-fda-guidance-documents/noninferiority-clinical-trials. Accessed 24 Jan 2020.

28. Goyal R, Jialal I. Diabetes Mellitus Type 2. [Updated 2019 Dec 20]. In: StatPearls [Internet]. Treasure Island (FL): StatPearls Publishing; 2020 Jan. https://www.ncbi.nlm.nih.gov/books/NBK51 $3253 /$.

29. Chawla A, Chawla R, Jaggi S. Microvasular and macrovascular complications in diabetes mellitus: distinct or continuum? Indian J Endocrinol Metab. 2016;20:546-51.

30. Sun Y, Zhou Y, Chen X, Che W, Leung S. The efficacy of dapagliflozin combined with hypoglycaemic drugs in treating type 2 diabetes mellitus: meta-analysis of randomized controlled trials. BMJ Open. 2014;4:e04619.

\section{Affiliations}

\section{Mala Dharmalingam ${ }^{1} \cdot$ S. R. Aravind ${ }^{2} \cdot$ Hemant Thacker $^{3} \cdot$ S. Paramesh ${ }^{4} \cdot$ Brij Mohan $^{5} \cdot$ Manoj Chawla $^{6}$. Arthur Asirvatham $^{7} \cdot$ Ramesh Goyal $^{8}$. Jayashri Shembalkar ${ }^{9} \cdot$ R. Balamurugan ${ }^{10} \cdot$ Pradnya Kadam $^{11} \cdot$ Hansraj Alva $^{12}$. Rahul Kodgule $^{13} \cdot$ Monika Tandon $^{13} \cdot$ Sivakumar Vaidyanathan $^{13} \cdot$ Amol Pendse $^{13} \cdot$ Rajesh Gaikwad $^{13}$. Sagar Katare ${ }^{13} \cdot$ Sachin Suryawanshi ${ }^{13} \cdot$ Hanmant Barkate $^{13}$}

Sagar Katare

sagar.katare@glenmarkpharma.com

MS Ramaiah Memorial Hospital, Bangalore, India

2 Diacon Hospital, Bangalore, India

3 Bhatia Hospital, Mumbai, India

4 Bangalore Diabetes and Diagnostic Centre, Bangalore, India

5 BMC Hospital and Diabetes Centre, Kanpur, India

6 Lina Diabetes Centre, Mumbai, India

7 Arthur Asirvatham Hospital, Madurai, India
8 Apollo Hospital, Ahmedabad, India

9 Getwell Hospital and Research Institute, Nagpur, India

10 Kovai Diabetes Speciality Centre and Hospital, Coimbatore, India

11 Inamdar Multispecialty Hospital, Pune, India

12 Vinaya Hospital and Research Centre, Mangalore, India

13 Medical Services, Glenmark Pharmaceuticals Ltd, Andheri East, Mumbai, Maharashtra 400 099, India 